\title{
Jogabilidade, aprendizados e emoções no jogo Violetas: cinema \& ação no enfrentamento da violência contra a mulher
}

\author{
Gameplay, learning and emotions in the board game Violets: \\ cinema \& action in combating violence against women
}

Maria Raquel Gomes Maia Pires (https://orcid.org/0000-0002-7941-0816) ${ }^{1}$
Alexandre Nascimento de Almeida (https://orcid.org/0000-0002-9113-0729) ${ }^{2}$
Leila Bernarda Donato Gottems (https://orcid.org/0000-0002-2675-8085) ${ }^{3}$
Rebeca Nunes Guedes de Oliveira (https://orcid.org/0000-0002-8784-9589) ${ }^{4}$
Rosa Maria Godoy Serpa da Fonseca (https://orcid.org/0000-0001-9440-0870) ${ }^{4}$

${ }^{1}$ Faculdade de Saúde, Universidade de Brasília (UnB). Campus Universitário Darcy Ribeiro s/n, Asa Norte. 70910-900 Brasília DF Brasil. maiap@unb.br

${ }^{2}$ Programa de PósGraduação em Gestão Pública, UnB. Brasília DF Brasil.

${ }^{3}$ Faculdade de Enfermagem, Universidade Católica de Brasília. Brasília DF Brasil. ${ }^{4}$ Departamento de Enfermagem em Saúde Coletiva, Escola de Enfermagem, Universidade de São Paulo. São Paulo SP Brasil.

\begin{abstract}
The board game Violets: cinema and action in combating violence against women was developed prioritising the liberating features of play to offer a setting for struggles to secure citizenship. The objective of the article was to examine the gameplay of Violets as regards players' understanding of the rules and engagement, and the game's mechanics and design; and to evaluate gameplay, emotions and learning comparatively as dimensions of play. This mixed method study proceeded in stages: a) perfecting gameplay: a workshop with 12 experts, usability tests with 33 participants and content analysis; and b) evaluating play: questionnaires for 78 participants and non-parametric Mann-Whitney U-test comparing groups of variables. Agreement among participants on aspects of gameplay was high. The group of gameplay variables returned values equal to those of the learning group; both differed significantly from the group for emotions felt while playing. In Violets, the interweave of gameplay with the formative, learning components set up a challenging, affective, symbolic field where players' imagination, interaction, tension and interest were expressed during play.

Key words Strategies, Education, Violence against women
\end{abstract}

Resumo O jogo de tabuleiro Violetas: cinema \& ação no enfrentamento da violência contra a mulher, forjado a partir da priorização das características libertárias do lúdico, ambienta lutas para a conquista da cidadania. O objetivo do artigo foi analisar a jogabilidade do Violetas quanto ao entendimento das regras, ao envolvimento das(os) jogadoras(es), à mecânica e ao design do jogo; e avaliar comparativamente as dimensões da jogabilidade, das emoções $e$ da aprendizagem como expressões da ludicidade. Pesquisa de métodos mistos, em etapas: a) aperfeiçoamento da jogabilidade: oficina com 12 especialistas; testes de usabilidade (33 participantes); análise de conteúdo; b) avaliação da ludicidade: questionários a 78 participantes, teste não paramétrico $U$ de Mann-Whitney para comparação dos grupos de variáveis. Os aspectos da jogabilidade obtiveram graus de concordância elevados entre as/os participantes. As variáveis da jogabilidade assumiram valor igual em relação ao grupo da aprendizagem, ambos significativamente diferentes de um grupo 2, das emoções sentidas na partida. No Violetas, o entrelaçamento da jogabilidade com os componentes formativos da aprendizagem viabilizam a criação de um campo simbólico, desafiador e afetivo em que a imaginação, a interação, a tensão e o interesse das(os) jogadoras(es) se manifestam durante as partidas.

Palavras-chave Estratégias, Educação, Violência contra a mulher 


\section{Introdução}

As expressões da cultura machista, sexista e discriminatória nas normas que regulam as relações sociais aprofundam a desigualdade entre os gêneros, tornando-a complexa, histórica e estrutural. As mulheres continuam a ser culpabilizadas ou constrangidas moralmente acerca das agressões que sofrem, em vista dos valores patriarcais impregnados nos discursos dos agentes públicos, das produções científicas, na cultura e na sociedade. As chamadas violências invisíveis, como a simbólica (coerções que se baseiam nos acordos não conscientes entre as estruturas objetivas e mentais das pessoas) e a institucional (aquela praticada por ação e ou omissão nas instituições prestadoras de serviços públicos), atestam o comprometimento do Estado na reprodução da violência ${ }^{1,2}$.

A reedição da violência contra a mulher pe$\operatorname{los}$ (as) profissionais de saúde figura nas produções internacionais e nacionais, com destaque para o viés autoritário, o despreparo e a reprodução de julgamentos morais na assistência à saúde. As principais situações em que essas agressões ocorrem são evidenciadas: i) no silenciamento que encobre a invisibilidade dos casos que chegam aos serviços; ii) na frágil responsabilização da equipe; iii) nos estereótipos de gênero e constrangimentos morais das práticas profissionais; iv) na violência obstétrica, injúrias e revitimização das mulheres provocadas pelo mau atendimento; v) no desconhecimento das políticas e das abordagens apropriadas para lidar com as mulheres agredidas; vi) na impotência de profissionais diante de situações de saúde multifatoriais; vii) nas abordagens restritas à medicalização do problema, entre outros ${ }^{3-5}$.

O caráter estrutural da violência requer abordagens sociais, educativas e políticas que superem as maneiras lineares, superficiais e simplistas de lidar com a problemática. Em perspectiva crítica, as saídas propostas para o enfrentamento da violência contra a mulher ressaltam as pressões dos movimentos sociais para a intersetorialidade das políticas públicas nas dimensões societais, comunitárias, interpessoais e individuais. As produções concordam com a necessidade de avançar na equidade das relações de poder entre homens e mulheres. Isso pode ser oportunizado prioritariamente por práticas pedagógicas que problematizam as desigualdades de gênero, especialmente na formação de profissionais que atuam na rede de enfrentamento da violência ${ }^{1,6-8}$.

No âmbito das políticas e práticas dos siste- mas de saúde, as revisões sugerem algumas premissas e estratégias para lidar com a violência, entre elas: i) a violência contra a mulher há de ser priorizada nas políticas de saúde; ii) as abordagens intersetoriais, interinstitucionais e em rede trazem melhores resultados; iii) o modelo biomédico é inadequado ao enfrentamento da violência; iv) preconizam-se abordagens centradas na desigualdade de poder entre os gêneros, em teorias críticas e inspiradoras do ativismo político; v) os movimentos de mulheres são centrais para os avanços; vi) são necessários investimentos em pesquisas, inovações e avaliações das intervenções, sob o enfoque do gênero; vii) há um consenso global de que profissionais necessitam de educação permanente para saber identificar, acolher, cuidar, encaminhar, acompanhar e gerir o cuidado com as mulheres que chegam aos serviços; viii) as estratégias pedagógicas ativas são bem avaliadas; ix) há necessidade de mudança na formação de profissionais de saúde para a desconstrução dos estereótipos de gênero ${ }^{6-8}$.

A educação em perspectiva crítica, capaz de se contrapor às práticas discursivas que violentam de maneira visível e invisível, pode ser uma estratégia para fortalecer a voz, a vez e a presença de nós, mulheres, nos espaços públicos ou privados, com vistas à cidadania. Isso porque as características inventivas do jogo dialogam com a educação questionadora e favorecem a imaginação reflexiva do pensar, como contraponto às abordagens pedagógicas tradicionais. Uma vez que o jogo se manifesta no caráter irreverente, disruptivo e criativo das relações humanas, aposta-se aqui num campo para a produção de sentidos libertos de fins disciplinares e imerso na singularidade das(os) envolvidos. Noutras palavras, práticas pedagógicas voltadas à experiencia do livre pensar humano são igualmente lúdicas, uma vez que brincam com a impossibilidade do real, tornando-o permeável às múltiplas interpretações e desejos de mudanças ${ }^{9-12}$.

Ao driblar conceituações mais rígidas (por coibir em seu caráter incerto), o lúdico se expressa de diferentes maneiras na cultura. Nas referências clássicas, a concepção de jogo se manifesta e transita entre a regra e a sua subversão; entre o fictício e o imaginário; entre a descontração e a tensão; entre o prazer e a dor; entre a espontaneidade e o disciplinamento das ações humanas, irreverente e imprevisivelmente. Tais elementos geram, multiplicam e subtraem imagens, símbolos e interpretações no mundo, as quais ampliam as experiências humanas dotadas de sentidos e de possibilidades criativas ${ }^{9-12}$. 
Entretanto, as vertentes positivistas das produções científicas sobre jogos limitam a formação crítica das(os) envolvidas(os), uma vez que: a) nelas, o sentido da experiência é esvaziado e subsumido a mero experimento; b) produz-se uma pretensa neutralidade axiológica do discurso científico, recoberto pelo inquestionável poder das evidências que reifica domínios imunes à crítica; c) as características libertárias do lúdico são inviabilizadas, seja por secundarizar a diversão em favor da aprendizagem disciplinadora, ou por esvaziar o sentido do agon (luta, disputa) a meras sensações artificiais de imersões, circunscritas ao poder da técnica. Em contraponto, a experiência a ser revigorada pelo jogo é justamente aquela que ficou fora do controle das variáveis, como recusa à repetição. Experimentar, no sentido lúdico que nos interessa, é abrir-se ao que não se repete, ao que estranha e exaspera, na mesma medida em que nos completa e faz transbordar o novo. Esse sentido mais intenso da experiência requer um aprofundar-se nas paixões, na tensão entre dor e prazer, um deixar-se aprisionar ambiguamente pelo que escraviza e liberta. Tal concepção do lúdico aposta no riso, no enfrentamento irônico e ambíguo com o "sério", como uma forma mais autônoma e livre de lidar com o universo espontâneo do jogar humano ${ }^{11-14}$.

$\mathrm{Na}$ tentativa de articular a autonomia das características do jogo com a educação reflexiva, criamos um tabuleiro em forma de rosa dos ventos. Nele, municípios brasileiros com nomes de mulheres lembram a força do feminino e ambientam as disputas por cidadania. As(os) jogadoras(es) envolvidas(os) nessa trama assumem papéis das personagens que integram as redes de enfrentamento da violência contra a mulher (a(o) operadora(r) de direito, a(o) educadora(r) e/ou a(o) pesquisadora(r); a(o) militante no movimento de mulheres; a(o) integrante de política pública e/ou profissional de saúde). Essa equipe tem uma missão: atuar colaborativamente para conter a violência (representada por fichas) que se espalha pelas cidades brasileiras (inscritas no desenho de rosa dos ventos que forma o tabuleiro). Isso ocorre sempre que as personagens retiram cartas-omissões que reeditam os estereótipos de gênero (ditados machistas, como: "todo feminismo acaba com o primeiro pneu furado") ou quando desconhecem aspectos relacionados à violência contra a mulher (erram as perguntas). A abstração imaginativa desse jogo dialoga com cenas de filmes para ambientar os desafios. $\mathrm{Ou}$ seja, a partir de contextos das cenas selecionadas, as(os) jogadoras(es) respondem questões sobre as políticas e as práticas de enfrentamento da violência contra a mulher. Caso as(os) participantes não consigam responder às questões ou agir em equipe para dirimir a violência (que avança com a retirada das cartas-omissões), todas(os) perdem imediatamente para o tabuleiro. A vitória acontece se a violência é combatida pela atuação colaborativa das(os) jogadoras(es).

Esse é o jogo Violetas: cinema \& ação no enfrentamento da violência contra a mulher, forjado a partir da força inventiva do lúdico como ambiência reflexiva acerca das lutas à conquista da cidadania para as mulheres. Nele, priorizamos o lúdico e favorecemos a sua manifestação o mais livre possível de fins disciplinares e conteudistas, por meio da jogabilidade que forja um campo simbólico imerso nas características libertárias do jogo. A jogabilidade (gameplay), conceito da área de design, investiga as especificidades da vivência da(o) jogadora(r) na partida e os recursos que podem favorecê-la ${ }^{13-16}$.

O presente estudo se justifica pela relevância do desenvolvimento de jogos centrados nas características autônomas do lúdico à formação de profissionais, como estratégia reflexiva sobre as desigualdades de gênero que violentam as mulheres. Argumentamos que a ludicidade - reinvenção imaginativa, livre e reflexiva de experiências forjadas ambiguamente nas afecções de prazer e de tensão do jogo - expressa-se na sua jogabilidade (se ele é dinâmico, interativo, inventivo, reprodutível, com terminalidade suficiente para manter o interesse das(os) jogadoras(es), nas emoções e na aprendizagem das(os) jogadoras(es) durante as partidas.

A questão central do artigo é a seguinte: a jogabilidade do Violetas possibilita a imaginação, a reflexão, a interação, a tensão e o interesse das(os) jogadoras(es) na partida. Os objetivos são: i) analisar a jogabilidade do Violetas quanto ao entendimento das regras, ao envolvimento das(os) jogadoras(es), à mecânica e ao design do jogo; ii) avaliar comparativamente as dimensões da jogabilidade, das emoções sentidas nas partidas e da aprendizagem formativa como expressões da ludicidade do jogo. Este estudo perfaz a segunda parte de uma pesquisa financiada pelo CNPq.

\section{Metodologia}

Pesquisa realizada com métodos mistos do tipo exploratório sequencial, recomendado na produção de jogos. Primeiramente aprofundamos os 
aspectos qualitativos da jogabilidade do Violetas, aperfeiçoando-a. Em seguida, o enfoque quantitativo auxiliou na avaliação comparativa de blocos de variáveis que perfazem as dimensões da ludicidade investigadas, a saber: jogabilidade, emoções e aprendizagens durante a partida. $\mathrm{Na}$ metodologia de produção de jogos, adotamos o referencial do Recriar-se Lúdico, por priorizar a centralidade dos componentes imaginativos e forjadores de subjetividades críticas nas(os) jogadoras(es). Dessa forma, as perguntas usuais desse tipo de produção são invertidas, uma vez que o interesse é ambientar, por meio de elementos forjadores e disruptivos do lúdico, os processos de reflexão nos(as) participantes - e não discipliná-los(as) em fins comportamentais. $\mathrm{O}$ Recriar-se Lúdico inclui três etapas na produção de jogos: a - concepção teórica do jogo; b - refinamento e avaliação da jogabilidade; $c$ - validação de constructo/critério da ludicidade. Neste artigo apresentamos os resultados referente à segunda etapa $^{13,17,18}$.

\section{Refinamento qualitativo da jogabilidade do Violetas}

Uma vez concebido e realizados os testes internos para os ajustes no protótipo do Violetas, a avaliação da jogabilidade ocorreu em dois momentos de investigação qualitativa. Inicialmente fizemos uma oficina com 12 especialistas da área de gênero e violência contra a mulher correspondentes às personagens do Violetas (operadoras(es) de direito, educadora(r) ou pesquisadora(r), profissionais de saúde/integrante de políticas públicas, militante no movimento de mulheres), no formato adaptado de um diálogo deliberativo. Esse método envolve conversações propositadas com stakeholders convidadas(os) a emitir pareceres sobre sua especialidade. Os processos deliberativos estimulam a produção compartilhada de conhecimentos específicos sobre um determinado tema ou produção sistematizada sobre um assunto, o que nos subsidiou no refinamentodo jogo ${ }^{19}$.

Nessa oficina de especialistas, as(os) participantes realizaram uma partida-teste do Violetas, divididos em três subgrupos, sem auxílio da equipe de pesquisa para o entendimento das regras, seguida de discussões num único grupo. Nessa ocasião, pedimos o parecer das(os) convidadas(os) quanto aos seguintes aspectos da jogabilidade: entendimento das regras, mecânica, envolvimento das(os) jogadoras(es) na partida e design do jogo. As discussões foram gravadas e anotadas por integrantes da equipe, que elaboraram as sínteses e fizeram leituras em voz alta para as(os) participantes, corrigindo-as e adequando -as ao registro do grupo.

Em seguida, ajustamos o jogo e realizamos 9 testes de usabilidade com grupos específicos, com uso de câmeras de vídeo para acompanhamento das partidas. Dessa forma, 33 participantes (estudantes, profissionais de saúde, educadoras(es), pesquisadoras(es), atuantes nas políticas públicas e no movimento de mulheres) realizaram sequencialmente 9 partidas-teste (playtest), uma por vez, numa sala monitorada por vídeo e observada pela equipe de uma outra sala. Os testes de usabilidade são oriundos da área de design e utilizados na produção de jogos de distintos formatos. Essa técnica é preciosa para os ajustes na jogabilidade, pois permite que observemos o envolvimento, a interação e as dificuldades das(os) jogadoras(es) durante uma partida. Para os 9 testes de usabilidade, utilizamos um roteiro de observação elaborado a partir de referências da área de design e engenharia de softwares, com as variáveis: a - terminalidade e reprodutibilidade; $\mathrm{b}$ - entendimento das regras; $\mathrm{c}$ - envolvimento; d - desafios do jogo; e - recepção das cartelas; $\mathrm{f}$ diário de campo ${ }^{20,21}$.

A sistematização de dados considerou as 10 partidas dessa etapa, uma delas a oficina de especialistas e os 9 testes de usabilidade monitorados por vídeo. Assim, o corpus investigativo correspondeu a esses 10 cenários. Fizemos análise de conteúdo do seguinte material: gravações de áudio dos depoimentos das especialistas e das sínteses elaboradas; registros do roteiro de observação do vídeo dos 9 testes de usabilidade. A apresentação dos resultados extraiu e quantificou as categorias empíricas do material, exemplificando sinteticamente os extratos de depoimentos e de observações que as ratificam ${ }^{22}$.

\section{Análise comparativa da jogabilidade, das emoções e da aprendizagem durante as partidas}

Após a fase qualitativa, realizamos novos ajustes no Violetas, deixando-o próximo da versão final, inclusive com a finalização do design gráfico (Figura 1). Seguiu-se a fase quantitativa com grupos de partidas-testes realizadas em sala de aula, na Universidade de Brasília (UnB), entre maio e novembro de 2015, numa amostra piloto de 78 participantes (estudantes de graduação das áreas de saúde, serviço social e antropologia). Após as partidas, as(os) jogadoras(es) responde- 


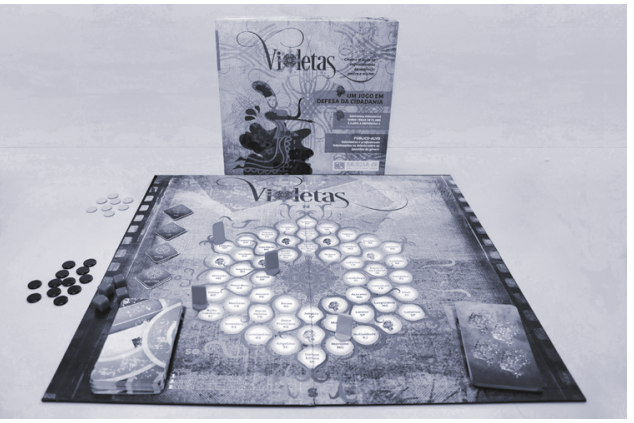

Figura 1. Jogo Violetas: cinema \& ação no enfrentamento da violência contra a mulher.

Fonte: Elaborado pelos autores.

ram a um questionário fechado de 53 itens de avaliação da ludicidade, mediante seu grau de concordância numa escala Likert, validado em investigações anteriores ${ }^{23}$.

Em vista dos objetivos e das premissas dessa investigação, selecionamos um conjunto de 33 variáveis do referido questionário para avaliar a ludicidade do Violetas, distribuídas em (Tabela 1): a - jogabilidade (ambiência lúdica); b - componentes formativos da aprendizagem (educação transformadora de si e das relações sociais num contexto formativo-crítico); c - emoções (afeto mobilizador) das(os) jogadoras(es) vividas na partida. Os critérios para a escolha dessas dimensões e variáveis foram: i) consonância com o referencial teórico do Recriar-se Lúdico e com os objetivos dessa investigação; ii) constructos e variáveis reconhecidamente relevantes e/ou validadas na literatura sobre jogos; iii) heurísticas de jogabilidade recomendadas nas produções; iv) resultados da etapa qualitativa desse estu-

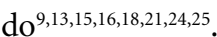

Na construção do banco de dados, utilizamos o pacote estatístico do Excel para Windows, com dupla inserção, seguida de conferência e unificação dos arquivos. Transpusemos os dados para o software IMB-SPSS, versão 22, para as análises estatísticas. Procedemos à análise descritiva das 33 variáveis, sob a forma de frequências, percentuais e medida de tendência central (mediana). A avaliação da ludicidade - expressa na jogabilidade, na aprendizagem e nas emoções vividas durante a partida - foi realizada segundo a comparação estatística das respectivas medianas em cada dimensão. Para isso, as variáveis foram formatadas de modo que todas as perguntas tivessem o mes- mo sentido e as respostas nos valores mais altos da escala de Likert indicassem maior jogabilidade, aprendizado e/ou emoções nas partidas. Em seguida, agrupamos os valores de cada dimensão em 3 grupos de variáveis compostas (jogabilidade, aprendizagem, emoções) e recalculamos as medianas. Realizamos, então, o teste não paramétrico U de Mann-Whitney para comparar cada um desses grupos, dois a dois. Verificamos a relação de importância significativa entre as variáveis do grupo 1 (jogabilidade) em relação ao grupo 2 (aprendizagem) e 3 (emoções), precedida do exame da dispersão pelo gráfico BoxPlot. Consideramos um valor de significância do teste $\mathrm{U}$ de $5 \%(\mathrm{p}=0,05)$ para o teste $\mathrm{U}$. Os testes não paramétricos são recomendados quando não se tem uma distribuição normal das variáveis, e o teste U de Mann-Whitney é indicado para a comparação de dois grupos não pareados. Ambos os critérios se aplicam a esta investigação, dada a característica da amostra piloto e os objetivos dessa fase da pesquisa ${ }^{26}$.

A pesquisa segue as diretrizes do Conselho Nacional de Saúde (CNS) e foi aprovada pelo comitê de ética da Faculdade de Ciências da Saúde da UnB. Todas(os) as(os) participantes assinaram o Termo de Consentimento Livre e Esclarecido (TCLE).

\section{Resultados}

\section{Aperfeiçoamento da jogabilidade do Violetas}

A média de tempo para leitura das regras foi de 25 minutos e a da partida foi 90 minutos. Das 10 partidas (cada grupo jogou uma partida de 1 h30 de duração em média), 3 grupos venceram, 2 perderam para o tabuleiro e 5 não chegaram ao final em virtude de compromissos das(os) participantes. Nas categorias empíricas extraídas para o entendimento das regras, as(os) jogadoras(es) tiveram dúvidas nos comandos básicos do Violetas em três partidas (30\%), mas essas dificuldades se diluíram após a leitura das regras $(50 \%)$ ou tiveram rápido entendimento $(20 \%)$. O caráter cooperativo contribuiu para o envolvimento das jogadoras(es) (50\%), em meio a sentimentos de prazer e tensão no jogo (40\%). O design foi considerado esteticamente agradável e recebeu elogios (70\%). Houve destaques positivos nos depoimentos para as "cartas-omissões", que no Violetas aumentam a violência no tabuleiro, assim como para as cenas de filmes, que ambientam as per- 
guntas. O jogo foi considerado complexo e com grau de dificuldade variado na metade das partidas realizadas (Quadro 1).

\section{Jogabilidade, aprendizados e emoções nas partidas do Violetas}

As(os) 78 respondentes ao questionário foram principalmente mulheres (92\%) entre $18 \mathrm{e}$ 23 anos $(82,7 \%)$ ou 23 a 29 anos (13\%), estudantes de graduação (95\%) de enfermagem $(48,7 \%)$, de serviço social $(23 \%)$ ou de ciências humanas - direito, gestão de políticas públicas, história, pedagogia, outros $(22,28 \%)$, além de graduados ou pós-graduados $(3,8 \%)$.
$\mathrm{Na}$ análise descritiva, a mediana das avaliações das(os) jogadoras(es) para a jogabilidade do Violetas assumiu o valor máximo da escala Likert $(\mathrm{med}=5,0)$. Essa tendência se repete para as altas concordâncias quanto ao design do jogo $(96,2 \%)$, a algo interessante que chamou atenção $(89,9 \%)$, ao desejo de jogar novamente $(83,6 \%)$ e à percepção de que o desempenho melhorou ao longo da partida $(81 \%)$. As variáveis de imersão na partida obtiveram mediana elevada $(4,0)$. Nessa medida, boa parte afirmou que se desligou do que acontecia ao redor $(65,7 \%)$, sentiu-se mais no ambiente do jogo $(68,4 \%)$ e achou que os desafios lhe prenderam a atenção $(67,1 \%)$. Alguns, porém, sentiram dificuldades em se concentrar

Quadro 1. Categorias empíricas extraídas a partir das partidas-teste do jogo Violetas, segundo variáveis e frequências dos depoimentos e observações nas partidas. Maio-dezembro, 2015.

\begin{tabular}{|c|c|c|c|}
\hline & Categorias empíricas & $\begin{array}{l}\text { Partidas } \\
\text { (P) n (\%) }\end{array}$ & Exemplaridades de depoimentos (D) e observações (OB) \\
\hline \multirow{3}{*}{ 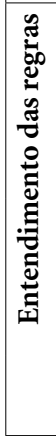 } & $\begin{array}{l}\text { Dúvidas nos } \\
\text { comandos básicos } \\
\text { do jogo, com } \\
\text { comprometimento da } \\
\text { jogabilidade }\end{array}$ & $3(30)$ & \multirow{3}{*}{$\begin{array}{l}\text { P9(D) “Depois que a gente entendeu ficou fácil”. } \\
\text { P10(D) “[...] a questão é que é um jogo muito mais complexo e essa } \\
\text { é a riqueza do jogo, se fosse um jogo muito mais simples eu acho que } \\
\text { isso se perderia" } \\
\text { P3(D) "Regras tranquilas, mas a gente sofreu com a estratégia". } \\
\text { P1(OB1) Dúvidas quanto à finalidade das peças redes-cidadãs e } \\
\text { impaciência durante a leitura das regras. } \\
\text { P9(OB3) Houve dificuldade para entender o que fazer com as } \\
\text { peças, sobretudo com as violetas-cidadãs. As participantes releram } \\
\text { as regras e avançaram no jogo. }\end{array}$} \\
\hline & $\begin{array}{l}\text { Dificuldades iniciais } \\
\text { no entendimento das } \\
\text { regras, porém o jogo } \\
\text { fluiu após releitura }\end{array}$ & $5(50)$ & \\
\hline & $\begin{array}{l}\text { Entendimento rápido } \\
\text { das regras }\end{array}$ & $2(20)$ & \\
\hline \multirow{2}{*}{ 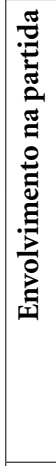 } & $\begin{array}{l}\text { Caráter cooperativo } \\
\text { e de estratégia do } \\
\text { jogo contribuiu para } \\
\text { o envolvimento na } \\
\text { partida }\end{array}$ & $6(60)$ & \multirow{2}{*}{$\begin{array}{l}\text { P10(D) “uma coisa bem legal é o fato de não ser um jogo competitivo, } \\
\text { de ser um jogo cooperativo, em que é o coletivo que ganha. O jogo na } \\
\text { verdade é um jogo divertido quando você entende a lógica, tanto que } \\
\text { o nosso grupo quando perdeu eu falei vamos jogar de novo, agora a } \\
\text { gente entendeu. Eu fiquei com vontade de jogar de novo e dessa vez } \\
\text { acertar como que joga de acordo com as regras". } \\
\text { P3(D) "Depois que começa a jogar fica bem interessante". } \\
\text { P5(OB1) Comentários de repúdio ao ler a carta de omissão "senta } \\
\text { que é de menta”. } \\
\text { P10(D) "O material serve para uma formação mais geral, tanto } \\
\text { porque trabalha com o cinema, um reportório, uma linguagem } \\
\text { universal." }\end{array}$} \\
\hline & $\begin{array}{l}\text { Ambiguidades entre } \\
\text { o prazer, a tensão, a } \\
\text { imersão e o tédio dos } \\
\text { jogadores durante a } \\
\text { partida }\end{array}$ & $4(40)$ & \\
\hline \multirow{2}{*}{ 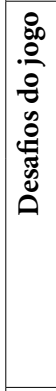 } & $\begin{array}{l}\text { Cartas-omissões } \\
\text { contribuíram para } \\
\text { manter o desafio e a } \\
\text { tensão no jogo }\end{array}$ & $5(50)$ & \multirow{2}{*}{$\begin{array}{l}\text { P10(D) "As cartas omissões provocam desconforto. Se era isso que vocês } \\
\text { queriam, vocês conseguiram. Quando a gente lia, é um chavão, é uma } \\
\text { coisa tão arraigada... é ao contrário de tudo o que se quer. Eu me senti } \\
\text { desconfortável." } \\
\text { P10(D) "Eu também achei as cartas omissões fantásticas, porque revela } \\
\text { essa coisa da piada. [...] Mas ali quando você ouve uma coisa que é tão } \\
\text { comum, que você se omite na maior parte das vezes que você ouve uma } \\
\text { piada ou um jargão, e a violência se instaura, aquilo assim realmente } \\
\text { provoca um mal-estar muito interessante". } \\
\text { P3(D) "É muito tenso porque quando a gente erra aumenta a violência". }\end{array}$} \\
\hline & $\begin{array}{l}\text { O desafio no jogo foi } \\
\text { considerado complexo, } \\
\text { com graus de } \\
\text { dificuldades variados. }\end{array}$ & $5(50)$ & \\
\hline \multicolumn{2}{|c|}{ Total de Partidas n (\%) } & $10(100)$ & \\
\hline
\end{tabular}

Fonte: Banco de dados da pesquisa. 
no texto das cartelas $(31,7 \%)$. Os componentes formativos da aprendizagem obtiveram a mediana das respostas no patamar máximo ( $\operatorname{med}=5,0)$. As(os) jogadoras(es) afirmaram que interagiram ativamente com as(os) colegas $(91,1 \%)$, fizeram associação do jogo com outras coisas $(88,7 \%)$, acharam que o Violetas lhes facilitou a aprendizagem $(86,1 \%)$, refletiram sobre os desafios que enfrentam na vida $(82,3 \%)$, aprenderam coisas surpreendentes com o jogo (76\%) e aumentaram o interesse no tema após a partida (76\%). Poucos acharam que o jogo inibiu a participação no grupo $(8,8 \%)$, foi indiferente ao aprendizado $(5,1 \%)$ ou que o texto das cartelas comprometeu o aprendizado (13,9\%), conforme Tabela 1 .

A mediana das emoções sentidas durante a partida manteve-se alta $(\mathrm{med}=4,0)$, seguindo a tendência das demais dimensões da ludicidade avaliada. No entanto, o valor máximo da mediana (med=5,0) figura entre aquelas(es) que gostaram do jogo $(87,4 \%)$, divertiram-se $(83,6 \%)$, ficaram motivados a continuar na partida $(82,3 \%)$, sentiram vontade de vencer e realizadas(os) com as conquistas do jogo (77,3\%). As medianas de valor 4,0 perfizeram as respostas dos sentimentos de descontração durante a partida $(74,7 \%)$, de ansiedade $(54,5 \%)$, de um misto de descontração e de tensão no jogo $(54,4 \%)$, de desestímulos frente aos desafios $(24,1 \%)$, na vontade de abandonar $(24,1 \%)$ ou naqueles que se disseram entediados $(17,4)$. Houve quem ficasse tenso $(43 \%)$ ou irritado com algumas coisas no jogo (38\%) (Tabela 1).

$\mathrm{Na}$ análise exploratória dos três grupos de variáveis referente às dimensões da ludicidade, o gráfico Boxplot revelou uma mediana elevadapara a aprendizagem $(5,0)$, em comparação com a jogabilidade $(4,0)$ e as emoções sentidas durante a partida $(4,0)$, quando consideradas como três blocos de variáveis compostas. A dispersão de cada um desses grupos transitou entre os valores de 3 a 5 na escala Likert, com relativo equilíbrio entre elas. No gráfico os valores variaram entre 1 e 5 (mínimo e máximo), porém, 50\% dos dados centrais se encontraram dentro da caixa (entre 3 e 5), demonstrando uma assimetria à direita (Gráfico 1).

A avaliação comparativa das variáveis segundo o teste $\mathrm{U}$ de Mann-Whitney mostrou que não há diferença estatisticamente significativamente para a jogabilidade e a aprendizagem (teste $U=218810,50, p=0,668$ ). No entanto, há diferença significativa para $1 \%$ quando comparamos a jogabilidade em relação às emoções sentidas durante a partida (teste $\mathrm{U}=333441,000$, $\mathrm{p}=0,000)$ e na comparação da aprendizagem com as emoções (teste $U=648440,00 ; p=0,000$ ), o que revela distinção entre esses grupos de variáveis. Com isso, as variáveis da jogabilidade assumem valores significativamente iguais em relação à aprendizagem, perfazendo um mesmo grupo 1 (Aprendizagem/Jogabilidade). No entanto, esse grupo é significativamente diferente do grupo 2 (Emoções), composto exclusivamente pelas variáveis correspondentes aos afetos (Quadro 2).

\section{Discussão}

As partidas realizadas com especialistas e com os nove grupos de testes de usabilidade permitiram o aperfeiçoamento gradual na jogabilidade do Violetas, especialmente em relação à reprodutibilidade e à terminalidade da partida, à mecânica, ao envolvimento das(os) jogadoras(es) e ao entendimento das regras. Face ao caráter cooperativo e de estratégia desse jogo, um dos aspectos a ajustar foi o grau de dificuldade, de modo a deixá-lo envolvente e dificultador o suficiente para manter a motivação das(os) jogadoras(es) em vencerem juntas(os) o tabuleiro. Nesse aspecto, ressaltamos a importância das cartas-omissões para a produção dos desafios e da tensão no Violetas, no âmbito da sua jogabilidade. Essa carta contém expressões e ditados populares machistas (por exemplo: "Você consente sem saber: Quem gosta de mulher feia é salão de beleza") que, uma vez retiradas do monte por algum(a) participante, aumenta imediatamente e irreversivelmente a violência no tabuleiro, gerando fortes reações emocionais. O impacto dela na partida é duplo: i) aumenta a dificuldade e a tensão na partida, em vista do risco eminente de derrota para todas(os); ii) chama atenção para as violências simbólicas e estruturais contra a mulher, naturalizadas em frases comuns do cotidiano. Ambas as características foram amplamente comentadas, observadas e discutidas entre as(os) participantes dessa etapa. A surpresa na derrota, evidenciada pela fala "vamos jogar de novo, agora que a gente entendeu!" (Quadro 1), exemplifica o envolvimento e a vontade de vencer o jogo, requisitos que foram ressaltados durante o aperfeiçoamento da jogabilidade ${ }^{21,24}$.

Ainda na etapa qualitativa, a análise de conteúdo demonstrou os aspectos centrais da jogabilidade bem avaliados pelas(os) participantes: a imersão na partida; o destaque para os componentes de estratégia e de cooperação para a manutenção do interesse; as ambiguidades nas 
Tabela 1. Ludicidade do Violetas segundo a jogabilidade, o aprendizado e as emoções sentidas durante a partida pelas/os jogadoras/es. Brasília, novembro, 2015.

\begin{tabular}{|c|c|c|c|c|}
\hline \multirow{3}{*}{ Variáveis por dimensão da Ludicidade } & \multicolumn{3}{|c|}{ Grau de concordância } & \multirow{3}{*}{ Mediana } \\
\hline & Discordo & Indiferente & Concordo & \\
\hline & $\mathbf{n}(\%)$ & $\mathbf{n}(\%)$ & $\mathbf{n}(\%)$ & \\
\hline Jogabilidade & & & & 5 \\
\hline $\begin{array}{l}\text { Eu me desliguei do que acontecia ao meu redor } \\
\text { enquanto jogava }\end{array}$ & $10(12,7)$ & $17(21,5)$ & $52(65,8)$ & 4 \\
\hline $\begin{array}{l}\text { Senti-me mais no ambiente do jogo que no mundo } \\
\text { real }\end{array}$ & $10(12,7)$ & $15(19)$ & $54(68,4)$ & 4 \\
\hline $\begin{array}{l}\text { Houve algo interessante no jogo que capturou minha } \\
\text { atenção }\end{array}$ & $4(5,1)$ & $4(5,1)$ & $71(89,9)$ & 5 \\
\hline O design do jogo chamou minha atenção & $3(3,8)$ & $0(0)$ & $76(96,2)$ & 5 \\
\hline $\begin{array}{l}\text { O jogo ofereceu novos desafios num ritmo que } \\
\text { prendeu a minha atenção }\end{array}$ & $8(10,2)$ & $18(22,8)$ & $53(67,1)$ & 4 \\
\hline Eu jogaria novamente esse jogo & $13(16,5)$ & $15(19)$ & $66(83,6)$ & 5 \\
\hline Meu desempenho melhorou com o desenrolar do jogo & $7(8,8)$ & $8(10,1)$ & $64(81)$ & 5 \\
\hline $\begin{array}{l}\text { Tive dificuldades de me concentrar no texto das } \\
\text { cartelas }\end{array}$ & $36(45,6)$ & $18(22,8)$ & $25(31,7)$ & 3 \\
\hline Componentes formativos da Aprendizagem & & & & 5 \\
\hline O jogo favoreceu a minha aprendizagem & $4(5,1)$ & $7(8,9)$ & $68(86,1)$ & 5 \\
\hline $\begin{array}{l}\text { Depois desta partida, o meu interesse pelo conteúdo } \\
\text { aumentou }\end{array}$ & $1(1,3)$ & $18(22,8)$ & $60(76)$ & 5 \\
\hline $\begin{array}{l}\text { Interagi ativamente com meus colegas durante a } \\
\text { partida }\end{array}$ & $2(2,5)$ & $5(6,3)$ & $72(91,1)$ & 5 \\
\hline $\begin{array}{l}\text { Eu fiz associação do conteúdo do jogo com outras } \\
\text { coisas }\end{array}$ & $4(5,1)$ & $5(6,3)$ & $70(88,7)$ & 5 \\
\hline O jogo inibiu a minha participação no grupo & $62(78,4)$ & $10(12,7)$ & $7(8,8)$ & 5 \\
\hline O jogo foi indiferente para o meu aprendizado & $71(89,8)$ & $4(5,1)$ & $4(5,1)$ & 5 \\
\hline $\begin{array}{l}\text { A dificuldade das cartelas comprometeu meu } \\
\text { aprendizado }\end{array}$ & $50(63,3)$ & $18(22,8)$ & $11(13,9)$ & 4 \\
\hline $\begin{array}{l}\text { Durante a partida, refleti sobre os desafios que } \\
\text { enfrentamos na vida }\end{array}$ & $4(5,1)$ & $10(12,7)$ & $65(82,3)$ & 5 \\
\hline Aprendi coisas surpreendente com o jogo & $7(8,8)$ & $12(15,2)$ & $60(76)$ & 5 \\
\hline Emoções durante a partida & & & & 4 \\
\hline Senti vontade de vencer a partida & $5(6,3)$ & $12(15,2)$ & $62(78,5)$ & 5 \\
\hline Tive vontade de abandonar a partida & $50(63,3)$ & $10(12,7)$ & $19(24,1)$ & 4 \\
\hline Eu me diverti ao jogar a partida & $6(7,6)$ & $7(8,9)$ & $66(83,6)$ & 5 \\
\hline O jogo me deixou tenso & $28(35,5)$ & $17(21,5)$ & $33(43)$ & 3 \\
\hline Eu gostei do jogo & $5(6,4)$ & $5(6,3)$ & $69(87,4)$ & 5 \\
\hline O jogo me deixou ansioso & $14(17,7)$ & $22(27,8)$ & $43(54,5)$ & 4 \\
\hline O jogo me manteve motivado a continuar na partida & $4(5,1)$ & $10(12,7)$ & $65(82,3)$ & 5 \\
\hline Os desafios do jogo me desestimularam na partida & $41(51,9)$ & $17(21,5)$ & $21(26,6)$ & 4 \\
\hline Achei a partida muito longa & $19(24,1)$ & $22(27,8)$ & $38(48,1)$ & 3 \\
\hline Fiquei entediado na partida & $51(64,5)$ & $14(17,7)$ & $14(17,7)$ & 4 \\
\hline Algumas coisas do jogo me irritam & $40(50,6)$ & $9(11,4)$ & $30(38)$ & 3 \\
\hline Fiquei descontraído durante a partida & $7(8,9)$ & $13(16,5)$ & $59(74,7)$ & 4 \\
\hline O jogo não me causou nenhuma emoção & $61(77,2)$ & $10(12,7)$ & $8(10,1)$ & 4 \\
\hline Senti um misto de descontração e de tensão no jogo & $21(26,6)$ & 15(19) & $43(54,4)$ & 4 \\
\hline $\begin{array}{l}\text { Achei-me incapaz por não saber responder as } \\
\text { perguntas }\end{array}$ & $53(67,1)$ & $8(10,1)$ & $18(22,8)$ & 4 \\
\hline Fiquei realizado com as conquistas no jogo & $9(11,4)$ & $9(11,4)$ & $61(77,3)$ & 5 \\
\hline
\end{tabular}


sensações de prazer e de tensão; os desafios crescentes como motivadores da partida; a sedução pela estética no design gráfico do Violetas. Essas características se sobressaíram no decorrer das partidas, à medida que as/os participantes entendiam as regras e a mecânica do jogo. Sem dúvida, as regras consideradas complexas e o jogo difícil foram fatores de desestímulo monitorado a cada partida, no intuito de aperfeiçoá-las gradualmente para que não se constituíssem numa barreira à jogabilidade ${ }^{16,18}$.

Acerca dessa dificuldade de entendimento das regras, cabe apontarmos alguns elementos contextuais. Primeiramente, visto que a violência é um fenômeno complexo e de difícil abordagem,

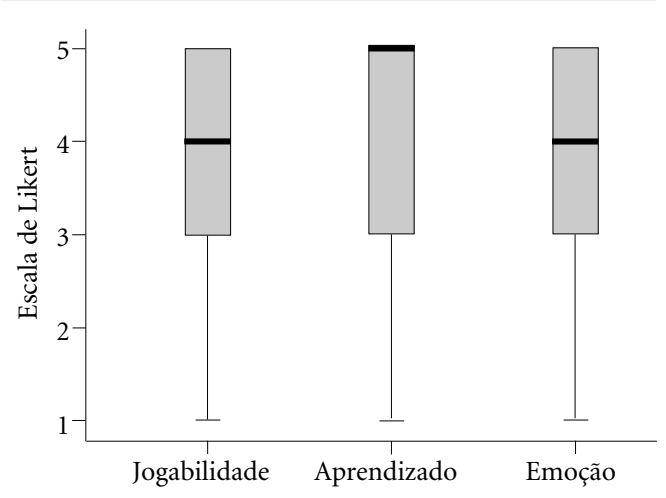

Gráfico 1. Dispersão exploratória e comparativa das variáveis agrupadas nas dimensões jogabilidade, aprendizagem e emoções sentidas durante as partidas. Brasília, outubro, 2019.

Fonte: Banco de dados da pesquisa.

Quadro 2. Comparação do grupo de variáveis da jogabilidade, da aprendizagem e das emoções sentidas na partida, segundo teste U de Mann-Whitney. Brasília, outubro, 2019.

\begin{tabular}{|c|c|}
\hline \multicolumn{2}{|c|}{ Grupos } \\
\hline $\mathbf{1}$ & $\mathbf{2}$ \\
\hline Aprendizagem & \\
\hline Jogabilidade & Emoções \\
\hline
\end{tabular}

Nota: Dimensões iguais dentro dos grupos ao nível de significância de 10\%. Grupo 1: Aprend/Joga: Teste U $=218810,50$, $\mathrm{p}=0,668$; Grupo 2: Joga/Emo: Teste $\mathrm{U}=333441,000, \mathrm{p}=0,000$; Aprend/Emocao: Teste $\mathrm{U}=648440,00 ; \mathrm{p}=0,000$.

Fonte: Banco de dados da pesquisa. optamos por desenhar um jogo que ambientasse à altura os desafios ao seu enfrentamento, especialmente no que se refere à labilidade das emoções. Nossos esforços foram no sentido de evitar um duplo risco: i) banalizar indevidamente as sérias agressões que as mulheres sofrem e suas graves repercussões; ii) acentuar demasiadamente o peso da violência, a ponto de elas abafarem a descontração do lúdico. A saída foi a criação de um jogo de tabuleiro do tipo moderno (eurogames), em que o caráter da estratégia e da cooperação se sobressaem aos elementos da sorte (alea $)^{11,27}$.

Ocorre que, com exceção de alguns nichos de casas especializadas nos jogos do tipo moderno, restritas aos grandes centros, a cultura lúdica no Brasil é predominantemente centrada nos tradicionais tabuleiros com trilhas definidas e uso de dados para a locomoção. O Violetas rompe com essas expectativas de um jogo com um percurso linear e centrado na sorte. Ele se apresenta como algo muito diferente do que habitualmente se vê (seu grande atrativo) e das experiências prévias do jogar, especialmente para o público feminino. Há que considerar, igualmente, a influência restritiva da misoginia presente na cultura dos gamers (jogadores frequentes e habituais), amplamente evidenciada nas pesquisas sobre o tema, como dificultador para maior familiaridade e habilidade das mulheres com o jogar. Diante disso, constatamos que o Violetas requer um tempo para que o campo do lúdico e do simbólico se estabeleça dentre as(os) participantes, a depender da presença desses fatores entre as(os) participantes $^{24,27-29}$.

Como todo jogo requer um processo natural de aprendizagem, os testes de usabilidade indicaram que, a depender do perfil e da performance de cada grupo, as dificuldades de entendimento do jogo eram vencidas à medida que as(os) jogadoras(es) adentravam no universo lúdico, com o progressivo aperfeiçoamento da jogabilidade. Vimos que as(os) participantes mais jovens ou com boa afinidade por jogos conseguiam entender mais rapidamente as regras e, portanto, adentrar rapidamente na imersão. Ao final dessa etapa, as heurísticas de jogabilidade estavam consolidadas, o que permitiu seguirmos para a avaliação da ludicidade, no entrelaçamento das dimensões da aprendizagem, da jogabilidade e das emoções sentidas na partida ${ }^{18,24,28,29}$.

Os resultados da fase quantitativa ratificam aqueles identificados na etapa qualitativa, expandindo-os para outros olhares complementares. No que tange à jogabilidade do Violetas, as características da imersão, do desempenho na par- 
tida, do interesse e da sedução estética do jogo se destacam. Se considerarmos o entrelaçamento da jogabilidade com a aprendizagem no jogo, atestada pela comparação estatística desses grupos de variáveis, vemos que o componente da interação, comum à jogabilidade, prevaleceu igualmente nas avaliações referente à aprendizagem. Frente à relevância da ambiência lúdica requerida para esse estudo, essa indissociabilidade entre as interações no jogo e nos processos de aprendizagem vivenciados pelas(os) participantes indica um embaralhamento entre a jogabilidade e a educação crítica desejável. Tais resultados sugerem que a tensão entre o jogo livre (imaginativo) e o instrumental (regulado), estabelecido ao redor do tabuleiro, possibilita aprendizados relacionados às associações com outras coisas, às reflexões sobre os desafios da vida, ao maior interesse na temática gênero e às descobertas surpreendentes no jogo, nas(os) participantes. Noutros termos, o "como se" (expressão indicativa para o jogo como um elemento de interação entre o fictício e o imaginário) do Violetas finge uma arena de disputas entre as violências e as cidadanias, sem um final definido e com múltiplas possibilidades interpretativas nas(os) participantes ${ }^{12,14}$.

Diante dessa mescla de sentidos entre o jogar e o aprender, a concepção de educação priorizada é aquela que emerge do entrelaçamento entre afeto, formação e resistência crítica. Numa possível síntese desses elementos, argumentamos pela relevância da experiência na produção dos aprendizados imaginativos, singulares, passionais e engajados, potenciadores de práticas discursivas críticas. A formação afetiva da resistência - articulada à compreensão da experiência como um pensar afetivo produtor de sentidos inusitados - pressupõe uma indissociabilidade entre o pendor reflexivo, os sentimentos e a prática política. Esses afetos transgressores se forjam numa perspectiva de educação que articula as singularidades com as análises teóricas, o que nos permite pensar, sentir e reconstruir de maneira ampliada. Numa tentativa de articular o pensamento feminista com a teoria da libertação, as produções teóricas nos instigam a falar e experimentar nossas dores - tanto para afunilarmos o espaço entre a teoria e a prática quanto para que elas se tornem práticas de cura e de resistência política, ${ }^{9,30}$.

Mas como seria possível "falar com a nossa dor" num jogo e, ainda assim, manter-lhe as características lúdicas? De que forma ultrapassar a superficialidade das emoções positivadas e unipolares da "gameficação" - espoliadora dos sentidos críticos - mantendo acesas as características libertárias do jogo? Como produzir um campo livre para que os afetos possam mobilizar sentimentos mais profundos (como a ansiedade), em sua tensão provocativa com as emoções, em volta de um simples tabuleiro com um desenho de rosa dos ventos (Figura 1)? De que forma as sensações do prazer e da dor, num jogo, poderiam provocar fissuras nas experiências, na busca desse pensar afetivo, incerto, inusitado e - por que não - transgressor?

No Violetas, nossa aposta para essas inquietações ocorre em meio ao diálogo das cenas de filmes com as questões temáticas colocadas para as(os) jogadoras(es), "como se" fosse um pano de fundo à conquista da cidadania para as mulheres. Vimos que essa estratégia entrelaçou as características da jogabilidade e dos aprendizados construídos pelas(os) as(os) envolvidas(os), despertando outros interesses e motivações potencializadores da ludicidade, em meio a sensações de prazer e tensão no jogo. Não por acaso, o resvalar do grupo de variáveis das emoções sentidas durante a partida - que nessa investigação se distingue da jogabilidade e da aprendizagem aponta para essa ambiguidade pretendida para os afetos, dando-lhes chance para outros possíveis e emocionados "jogos livres" em volta do tabuleiro. Esse resultado sugere que o Violetas abre espaço para que os sentimentos brinquem com nossas tentativas de aprisioná-los objetivamente, dando vazão a sentidos não capturáveis pela estatística porém necessários à produção de interpretações imaginativas, reflexivas, críticas e emocionadas nas(os) jogadoras(es) ${ }^{9-16}$.

\section{Conclusão}

No jogo Violetas, o entrelaçamento da jogabilidade com os componentes formativos da aprendizagem viabilizam a criação de um campo simbólico, desafiador e afetivo em que a imaginação, a interação, a tensão e o interesse das(os) jogadoras(es) se manifestam durante as partidas. Com isso, as reflexões sobre o enfrentamento da violência contra a mulher amplificam as possibilidades da experiência vivenciada pelas(os) envolvidas(os), fazendo-as coincidir com as premissas da educação crítica, da criatividade e da luta política. Ao apostar nos elementos subversivos do jogo como ambiência disruptiva, aberta e estimulante para as(os) que dele participam, o Violetas rompe com as expectativas lineares e conteudistas das produções científicas sobre jogos, invertendo epistemologicamente as premis- 
sas em favor dos elementos libertos, imprecisos e emotivos do lúdico. Por consequência, a inquietude do jogo, a reinvenção dos aprendizados e a ambiguidade das emoções são lançadas imprevisivelmente no Violetas, sem a presença de qualquer dado sobre o tabuleiro.

\section{Colaboradores}

MRGM Pires trabalhou na concepção, pesquisa e na elaboração de todo o artigo. AN Almeida realizou a análise estatística dos dados e contribuiu com as discussões. LBD Gottems, RNG Oliveira e RMGS Fonseca fizeram a revisão crítica e agregaram contribuições ao texto. 


\section{Referências}

1. Htun H, Weldon L. The Logics of Gender Justice: State Action on Women's Rights around the World. New York: Cambridge University Press; 2018.

2. Montesanti SR, Thurston WE. Mapping the role of structural and interpersonal violence in the lives of women: implications for public health interventions and policy. BMC Women's Health 2015; 15(1):1.

3. Virkki T. Social and health care professionals' views on responsible agency in the process of ending intimate partner violence. Violence Against Women 2015; 21(6):712-733.

4. Khumisi ET, De Wall M, Van Wyk NC. Educating nurses on intervention in and prevention of intimate partner violence: A systematic review. Afr J Physical Health Educ Recreation Dance 2015; Supl. 1(2):369384.

5. Vieira EM, Hasse M. Percepções dos profissionais de uma rede intersetorial sobre o atendimento a mulheres em situação de violência. Interface (Botucatu) 2017; 21(60):51-62.

6. García-Moreno C, Hegarty K, D’Oliveira AFL, Koziol -McLain J, Colombini M, Feder G. The health-systems response to violence against women. Lancet 2015; 385:1567-1579.

7. Michau L, Horn J, Bank A, Dutt M, Zimmerman C. Prevention of violence against women and girls: Lessons from practice. Lancet 2015; 385(9978):16721684.

8. Ellsberg M, Arango DJ, Morton M, Gennari F, Kiplesund S, Contreras M, Watts C. Prevention of violence against women and girls: What does the evidence say? Lancet 2015; 385(9977):1555-1566.

9. Hooks B. Ensinando a transgredir: a educação como prática da liberdade. São Paulo: Martins Fontes; 2013.

10. Huizinga J. Homo Ludens: o jogo como elemento da cultura. $5^{a}$ ed. São Paulo: Perspectiva; 2008.

11. Caillois R. Os homens e os jogos: a máscara e a vertigem. Lisboa: Cotovia; 1990.

12. Iser W. O fictício e o imaginário: perspectivas de uma antropologia literária. 2a ed. Rio de Janeiro: Uerj; 2017.

13. Pires MRGM, Gottems LBD, Fonseca RMGS. Recriar-se lúdico no desenvolvimento de jogos na saúde: referências teórico-metodológicas à produção de subjetividades críticas. Texto Contexto Enferm 2017; 26(4):e2500017.

14. Simon B. Unserious. Games Culture 2016; 12(6):605618.

15. Pires MRGM, Silva LVS, Fonseca RMGS, Oliveira RNG, Gessner R, Gouveia EP. Violetas: cinema \& ação no enfrentamento da violência contra a mulher: concepção de subjetividade, gênero, cidadania e ludicidade nas regras e nas cartas do jogo. RICS 2017; 3(n. esp.):99-115.

16. Frome J. Interactive Works and Gameplay Emotions. Games Culture 2019; 14(7-8):856-874.
17. Creswell JW, Clarck VLP. Pesquisa de métodos mistos. Porto Alegre: Penso; 2013.

18. Zimmerman E, Salem K. Regras do jogo: fundamentos do design. São Paulo: Blucher; 2012.

19. Plamondon KM, Bottorff JL, Cole DC. Analyzing data generated through deliberative dialogue: bringing knowledge translation into qualitative analysis. Qual Health Res 2015; 25(11):1529-1539.

20. Preece J. Design de interação: além da interação humano-computador. Porto Alegre: Bookman; 2005.

21. Bernhaupt R. Game user experience evaluation. In: Human-Computer Interaction Series [Internet]. New York: Springer; 2015 [acessado 2019 maio 10]. Disponível em: http://www.springer.com/series/6033.

22. Sampieri RH, Collado CH, Lucio PB. Metodologia de pesquisa. São Paulo: Mcgraw-Hill; 2006.

23. Pires MRGM, Gottems LBD, Silva LVS, Carvalho PA, Melo GF, Fonseca RMGS. Desenvolvimento e validação de instrumento para avaliar a ludicidade de jogos em saúde. Rev Esc Enferm USP 2015; 49:981-990.

24. Barbara J. Measuring User Experience in Multiplayer Board Games. Games Culture 2015; 12(7-8):623-649.

25. Petri G, Wangenheim CG. How to Evaluate Educational Games: a Systematic Literature Review. J Universal Computer Sci 2016; 22(7):992-1021.

26. Maroco J. Análise Estatística com o SPSS Statistics. 6a ed. Pero Pinheiro-PT: Repport Number; 2014.

27. Woods S. Eurogames: the design, culture and play of modern European board games. London: McFarland; 2012.

28. Ochsner A. Reasons Why: Examining the Experience of Women in Games 140 Characters at a Time. Games Culture 2017; 14(5):523-542.

29. Gestos M, Smith-Merry J, Campbell A. The Representation of Women in Video Games: A Systematic Review of Literature in Consideration of Adult Female Wellbeing. Cyberpsychol Behav Soc Netw 2018; 21(9):535-541.

30. Bondia JL. Pedagogia profana: danças, piruetas e mascaradas. Belo Horizonte: Autêntica; 2015.

Artigo apresentado em 25/10/2019

Aprovado em 19/05/2020

Versão final apresentada em 21/05/2020

Editores-chefes: Romeu Gomes, Antônio Augusto Moura da Silva 